Europe's Journal of Psychology 2/2010, pp. 47-64

www.ejop.org

\title{
Retirement context and psychological factors as predictors of well-being among retired teachers
}

Samuel O. Salami

Department of Guidance and Counselling, Kampala International University

\begin{abstract}
This study investigated the relationship of retirement context and psychological factors with well-being using data on 284 retired married men and women (aged 52-75 years). Measures of retirement context, psychological factors and well-being were used to obtain data from the retirees. Findings show that retirement status, job challenges, financial situation, physical health, activity level, and social support separately predicted psychological well-being. However, there were no significant effects of marital quality and social status on psychological well-being. Results also revealed that preretirement expectations, self efficacy, perceived stress, and optimism separately predicted psychological well-being. Interaction effects of retirement status and job challenges with gender predicted life satisfaction but not depressive symptoms. The results indicate the importance of examining the contextual and psychological factors in understanding the relationship between retirement status and psychological well-being.
\end{abstract}

Keywords: Retirement context, life satisfaction, depressive symptoms, teachers, self efficacy

\section{Introduction}

Retirement has been viewed as one of the later life status transitions although our knowledge of its psychological consequences is fragmentary (Kim \& Moen, 2002). It is an objective development and social-psychological transformation that is related to physical and psychological well-being (Moen, 2001).Retirement may promote a sense of well-being of workers moving out of demanding and /or stressful career jobs. On the other hand, it may lead to diminished well-being for individuals who lose their occupational attachments, social networks and identities (Kim \& Moen, 2002). 
With respect to psychological consequences of retirement, empirical evidence is inconsistent. For instance, some researchers have found significant negative relationship between retirement and life satisfaction or morale (Kim \& Moen, 2002; Taylor, Goldberg, Shore \& Lipka, 2008) and positive association with psychological distress (Kim \&Moen, 2002; Okatahi, 2007; Onyewotu, 2005; Salami \&Oduntan, 2001). Other researchers found no negative psychological effects such as psychological distress associated with retirement (Gall, Evans \& Howard, 1997; Ross \& Drentea, 1988). Some have reported mixed findings. For example, Gall, Evans and Howard (1997) found no relationship between retirement and life satisfaction while a positive effect of retirement on health or reduced stress level was found by Midanik, Soghikian, Ramson and Tekawa (1995).

Although increasing research attention has been focused on predisposing factors of psychological well-being in retirement, there are inconsistencies in the results obtained. There are several contending explanations, in view of existing literature, on the factors affecting the psychological well-being of retirees that required further research (Kim \&Moen, (2002). Also many earlier studies focused almost exclusively on men's retirement with little investigation of women's experiences. Recent increases in women's workforce participation along with increased longevity and decreased retirement age point to the need to consider retirement as a couple phenomenon. Therefore, there is need to examine various resources and contexts surrounding retirement in order to understand the dynamics of retirement transition and its relationship with psychological well-being. The purpose of this study was to investigate relationships of psychological factors (retirement expectations, selfefficacy, perceived stress, and optimism) and retirement context (resources and circumstances around retirement) on the psychological well-being of retired teachers.

Theoretical framework

This study was based on two theoretical frameworks (the role theory and the continuity theory) to understand the effects of some social-psychological factors on the psychological well-being of retired teachers. Role theory (George, 1993) provides one of the commonest explanations of adjustment to retirement (Moen, 2001). The main argument of role theory is that loss of work as in retirement results in decline in life satisfaction and increase in depressive symptoms. From the role theory, perspective men and women who retire from their career jobs are susceptible to role loss, which can lead to psychological distress (Kim \& Moen, 2002). The role theory postulates that employment is central to one's identity; loss of this important work 
role, and /or the environmental loss accompanying retirement, produces decline in morale or life satisfaction and increase in depressive symptoms.

Another perspective of the role theory is that retirement from the demands of one's primary career job may be a major life-course role exit that serves to reduce role strain and overload, thereby enhancing psychological well-being (Kim \& Moen, 2002). The role-strain reduction theoretical perspective indicates that circumstances around employment, retirement and the transition from one to the other should be considered (Kim\& Moen, 2002; Vandewater, Ostrove, \& Stewart, 1997) when examining the well-being of retirees.

Continuity theory (Richardson \& Kilty, 1991) states that people tend to maintain earlier lifestyle patterns, self-esteem, and values even as they exit their primary career jobs. Retirement, therefore need not lead to maladjustment and distress. George and Maddox (1977) found a great stability in life satisfaction among older men over a five year period.

Retirement context

Retirement brings about changes in couples' financial situation. Research findings have shown that lack of financial resources correlates negatively with the ease of adjustment in terms of postretirement satisfaction and well-being (Ardelt, 1997; Gallo, Bradley, Siegel \& Henkens, 2005). It is assumed that the couple's ability to maintain their pre-retirement life style is important to their retirement adjustment process. Since the financial situation of retirees tends to be low in Nigeria, it is expected that financial decline after retirement will constitute problems in relation to retirement adjustment. It is, therefore, hypothesized that financial situation will predict the psychological well-being among retired teachers $\left(\mathrm{H}_{1} \mathrm{a}\right)$. The better the financial situation of retirees the better will be their psychological well-being.

Poor health status of retirees may disrupt adjustment to retirement because poor health condition of one of the marriage partners may restrict them from taking up new activities and hinder adjustment to retirement (Van Solinge \& Henkens, 2005). Health status was found to be significantly correlated with life satisfaction (Ardelt, 1997; Kim \& Moen, 2002) and depressive symptoms of retirees (Kim \& Moen, 2002). A poor health condition of one of the retired partners means demanding care responsibilities which may place additional strains on the relationship and subsequently hinder retirement adjustment. Therefore, it is proposed that physical health will predict the psychological well-being among retired teachers $\left(H_{1} b\right)$. The 
better the health status of the retirees, the greater their psychological well-being.

Greater involvement in leisure activities prior to retirement facilitates adjustment to retirement (Van Solinge \& Henkens, 2005). Previous researches have shown that level of activity and leisure activities were significantly related to depression (Okatahi, 2007) and life satisfaction (Lee \& Lin, 2009; Van Solinge \& Henkens, 2005). It is expected that a greater involvement in leisure activities will facilitate adjustment to retirement. Therefore, it is proposed that: Activity level will predict psychological wellbeing among retired teachers $\left(H_{1} \mathrm{C}\right)$. The higher the activity level of retirees the better their psychological well-being.

Marital quality is an important resource in the process of adjustment to retirement or psychological well-being. Research findings have shown that marital quality was significantly related to life satisfaction and depression (Kim \& Moen, 2002) and adjustment to retirement (Van Solinge \& Henkens, 2005). It is found by Myers and Booth (1998) that couples with less satisfying marriages may be less well positioned to weather retirement adjustment. Therefore, it is proposed that: Marital quality will predict psychological well-being among retired teachers $\left(H_{1} d\right)$. The better the marital quality of retirees, the better their psychological well-being.

Social support can be considered as the type and frequency of social contacts. It is also the degree to which a person perceives that certain types of support le.g. emotional, tangible assistance) are available. Both types of social support have been directly linked to life satisfaction and retirement satisfaction (Ardelt, 1997; Aquino, Russell, Cutrona \& Altmaier, 1996; Taylor, Goldberg, Shore \& Lipka, 2008). It is expected that the more the retirees' social networks the easier adjustment to retirement will be. Therefore, it was hypothesized that: Social support will predict the psychological well-being among retired teachers $\left(H_{l} e\right)$. The higher the social support available to retirees the better their psychological well-being.

Social status is determined by one's occupational prestige. It is an aspect of wellbeing due to the feeling of being superior to others in the view of relevant others and oneself (Van Solinge \& Henkens, 2005). After retirement, social status is reduced since occupational prestige is also reduced. Ardelt (1997) found significant relationship between social status and life satisfaction of retirees however; Van Solinge and Henkens (2005) did not find significant effects of social status on adjusting to retirement. Therefore, it is hypothesized that: Social status will predict psychological well-being of retired teachers $(\mathrm{H}, \mathrm{f})$. The higher the social status among retired teachers before retirement, the poorer their psychological well-being. 
Circumstances around retirement have effects on retirees' psychological well-being. Unanticipated and involuntary retirement have negative effects on retirees' wellbeing (Marshall, Clarke \& Ballantyne, 2001; Van Solinge \& Henkens, 2005). People who were forced to retire may have adjustment problems at retirement. Therefore, it is hypothesized that retirement status will predict psychological well-being among retired teachers $\left(H_{1} g\right)$. Teachers who had voluntary retirement will have better psychological well-being. Individuals who have job challenges will feel less positive about leaving their jobs (Taylor \& Shore, 1995). Researches have shown that people who had more job challenges had negative adjustment or poor psychological wellbeing and depressive symptoms (Van Solinge \& Henkens, 2005). Therefore, it is hypothesized that job challenges will predict psychological well-being of retired teachers $\left(H_{1} h\right)$. The higher the job challenges among retired teachers, the poorer their psychological well-being.

Gender is another contextual factor in retirees' psychological well-being. Difficult work histories, employment opportunities and general life experiences may cause women to adjust to retirement differently than men do. There is evidence that women have more negative attitudes toward retirement than men do, and retirement is more disruptive and more likely to be linked with greater depression and loneliness for women than it is for men (Kim \& Moen, 2002). Because there are gender- based differences in work commitment caused by the fact that women's primary role was in the home, retired women are expected to have fewer adjustment problems (Slevin \&Wingrove, 1995). Therefore, it is hypothesized that: Gender will moderate relationship between retirement status and psychological well-being in favour of women such that the relationship will be stronger for female retirees than for female retirees than for male retirees $\left(\mathrm{H}_{2}\right)$. Gender will moderate the relationship between job challenges and psychological well-being among retired teachers such that the relationship will be stronger for female retirees than for male retirees $\left(\mathrm{H}_{3}\right)$. Gender will moderate the relationship between pre-retirement expectations and psychological well-being among retired teachers such that the relationship will be stronger for the female retirees than for male retirees $\left(\mathrm{H}_{4}\right)$.

Psychological factors

Pre-retirement expectations are important determinants of retirement decisions and play major roles in how retirement and adjustment process unfolds (Gall \& Evans, 2000). Research evidence have indicated that expected outcomes of retirement such as financial, health, social status, leisure time activity, and social contacts have significant influence on psychological well-being/adjustment of retirees (Gall \& 
Evans, 2000;Taylor, Goldberg, Shore \& Lipka, 2008; Van Solinge \& Henkens, 2005). Therefore, it is hypothesized that pre-retirement expectations will predict psychological well-being among retired teachers $\left(\mathrm{H}_{5} \mathrm{a}\right)$. The higher the pre-retirement expectations of retired teachers the better their psychological well-being. Selfefficacy is the belief that one can effectively perform a given task in a given situation (Bandura, 1982). Since retirement is a new experience, self-efficacy will likely be associated with ease of adjustment. Research has shown that self-efficacy was significantly correlated with retirement adjustment (Van Solinge \& Henkens, 2005). Therefore, it is hypothesized that self-efficacy will predict psychological well-being among retired teachers $\left(\mathrm{H}_{5} \mathrm{~b}\right)$.The higher the self-efficacy among retired teachers the better their psychological well-being.

Stress is physical or psychological demand to which an individual responds. Okatahi (2007) found that a major stress precipitated a severe depression in retirees. Therefore, it is hypothesized that stress will predict psychological well-being among retired teachers $\left(\mathrm{H}_{5} \mathrm{C}\right)$. The higher the stress levels among retired teachers the poorer their psychological well-being. Optimism is a generalized tendency to expect positive outcomes (Scheier \& Carver, 1993). Given the pervasive impact of expectations on retirement adjustment, it is expected that optimism will have a significant relationship with psychological well-being of retirees. Optimism has significant relationship with psychological well-being of retirees. (Taylor et al. 2008). Therefore, it is hypothesized that stress will predict psychological well-being among retired teachers $\left(\mathrm{H}_{5} \mathrm{~d}\right)$. The higher the level of optimism among retired teachers, the better their psychological well-being.

Method

Participants

The participants for the study consist of 284 retired teachers 176 men $\quad$ (61.97\%) and 108 women (38.8\%) from the Kwara State, Nigeria. The average age of the sample was 63.50 years $(S D=5.32)$ with a range from 52 to 75 years. All participants volunteered for the study and all were assured that their responses were confidential. Fifty one (17.96\%) retired teachers had Teachers' Grade 11 Certificate, 170 (59.86\%) had Nigeria Certificate in Education, N.C.E., 43(15.14\%) had degrees while 20 (7.04\%) had postgraduate Diploma in Education (PGDE). 
Measures

Financial situation. Financial situation is measured by a single variable. "What is your financial situation presently?" Response to the question ranges from 0-100 on which 0 represents completely inadequate and 100 represents more than adequate.

Social status. This was measured by means of a composite of the following two items: (a) Highest education ranging from $1=$ (primary six certificates) to $7=$ (Doctor of Philosophy Degree, Ph.D) on a 7-point scale;

(b) Longest held occupation (1=labourer, messenger, skilled or unskilled; 2=clerks, sales or secretarial, housewife; 3=small business owner, supervisor, teacher; 4=executive in a company with 50 or more employees; $5=$ professional workers; $6=$ lecturer).

The scores of the two items (highest education and longest held occupation) were averaged after the first items were transformed into a score from 1 to 5 (Ardelt, 1997).

Physical health. This variable was derived from the respondents' self-evaluation and reports of health condition. Respondents rated their health status on a two-item scale ranging from 0 (very serious health problems) to 10 (very good health) (Kim \& Moen, 2002). Examples of items for physical health are: "What is your general state of health?" (Answer categories ranged from 0 (Very serious health problems to 10 (very good health)". "Has your health changed since retirement?" answer categories ranged from 1 (yes, much worse) to 10 (yes, much better).

Marital quality. Marital quality was assessed using the sum of two items of marital satisfaction and marital -conflict frequency. Marital satisfaction was assessed using the response to the single question "taking all things together, how satisfied are you with your marriage?" on a five point scale ranging from completely satisfied (5), to not at all satisfied (1). Marital conflict was assessed from answer to the question, "How often would you say the two of you typically have serious disagreements or conflict?" on a five point scale ranging from more than once a week (5) to never (1). Higher scores indicate higher marital quality. The two measures of marital quality are significantly and negatively correlated with each other $(r=-.36 p<.05)$.

Retirement status. Information on the nature of retirement or circumstance around retirement was derived from 4items on a five point scale ranging from $1=$ completely agree to 5= completely disagree. Examples of items are: "I was reluctant to retire"; "My decision to retire was and voluntary". 
Job challenges. Information on job challenge was derived from 3 items on a five point scale ranging from $1=$ completely agree to $5=$ completely disagree that assess whether work was boring, routine for the retiree before retirement. Examples of items for Job challenge are: "The work I was doing was not very challenging"; "The work I am doing has become more boring and routine". The Cronbach's alpha for this scale for the present study was .75.

Social support. Social support was assessed by the Social Provisions Scale (SPS) by Cutrona \& Russell (1987). It measures six relational provisions as obtained from the retired teachers' social relationships. The respondents indicate their degree of agreement (1) or disagreement (0) if they feel the statements are true of their current relationships with friends, family members, colleagues, previous school organization and community members. The six provisions according to Cutrona and Rusell (1987) are: Attachment, Reliable alliance, Guidance, Advice or Information, Opportunity for nurturance, Reassurance of worth and Social integration. The Cronbach's alpha coefficient for the six sub-scales for this study ranged from .61 to .76.

Activity level. Level of activity was assessed from the respondents' answer to the question, "On which of the following activity do you spend your free time? (16 categories). Answers to 1 question concerning leisure activities of retirees range from 0 tol2.

Retirement expectations. Retirement expectations scale was a five item scale based on the work of Taylor and Shore (1995) and Van Solinge \& Henkens (2005) that used a five -point Linkert scale ranging from $1=$ strongly agree to 5 =strongly agree. The Cronbach's alpha coefficient for this scale in this study was .83.

Self-efficacy. Self-efficacy was measured using Generalised Self-Efficacy Scale (GSES,Schwarzer \& Jerusalem, 1995).GSES is a 10-item scale that assessed selfefficacy based on personality disposition. It is measured on a 4-point Likert scale ranging from $1=$ not at all true to $4=$ exactly true. The Cronbach's alpha coefficient of GSES range from .75 to .90 for this study.

Perceived stress. Cohen's Perceived Stress Scale-10 (PSS-10; Cohen, Kamarck \& Marmelstein, 1983) was used to assess the degree to which each participant perceives his or her experience and environment to be stressful. The PSS-10 is a short, 10-item Likert -type self-report scale. For this study the Cronbach's alpha coefficient obtained for PSS-10 was .82. 
Optimism/pessimism. The Life Orientation Test-Revised (LOT-R, Scheier, Carver \& Bridges, 1994) was used to assess optimism/ pessimism. The LOT-R is a 10-item scale with 4 filler items and six scale items. The respondents responded on a 4-point scale with end-points of strongly agree (4), and strongly disagree (1). Higher scores indicate more optimism and more pessimism respectively). In this study, the following Cronbach's alpha coefficients were found: .66, and .77 for optimism and pessimism respectively.

Demographic characteristics. Data on demographic characteristics of the respondents were collected via a demographic questionnaire. Characteristics addressed by the questionnaire were age, gender, higher academic qualifications, teaching experience, job ranks, and marital status.

Depressive symptoms. The Centre for Epidemiologic Studies Depression Scale (CES-D; Radloff, 1977) was used in this study to collect data on depression. CES-D is 20- item brief self-report scale which assesses depressive symptoms experienced by the sample during the past week. Participants responded to the 20 items on a four-point Likert-type scale. Higher scores indicate greater reported symptoms of depression. For this study, the Cronbach's alpha coefficient was found to be .86 .

Life satisfaction. The Life Satisfaction Index-Version (DSI-A) developed by Neugarten, Havighurst and Tobin (1961) was used to measure life satisfaction. LSI-A is a 20-item questionnaire that provided an accumulation score acknowledged as a valid index of quality of life. It used the Likert five -point scales ranging from $1=$ strongly disagree to $5=$ strongly agree. For this study the Cronbach's alpha found was. 90 .

Procedure

The study adopted a survey research design in which questionnaires were used to obtain data information from the respondents. Five research assistants were trained for the purpose of the study. During the study, the researcher and the research assistants went round the local government areas in Kwara state during the administration of the questionnaires. The questionnaires were administered through the cooperation of some officials of the retired teachers' unions. 
Results

Data analysis

The data collected were analysed using series of hierarchical multiple regression analyses. The independent variables were contextual factors (circumstances around retirement; retirement status job challenges, resources and socio-economic status) and psychological factors (pre-retirement expectations, self-efficacy, stress and optimism).The dependent variables were life satisfaction and some officials of the retired teacher's unions.

Correlation analyses

Table 1 represents the descriptive statistics for the variables under study as well as the bivariate correlations between contextual and psychological variables and psychological well- being of retired teachers.

Table 1: Intercorrelation Matrix of contextual and psychological variables and psychological well-being of retired teachers

\begin{tabular}{|c|c|c|c|c|c|c|c|c|c|c|c|c|c|c|c|c|}
\hline \multicolumn{17}{|l|}{ variables } \\
\hline $1 \mathrm{FS}$ & 1.00 & & & & & & & & & & & & & & & \\
\hline $2 \mathrm{AL}$ & -.07 & 1.00 & & & & & & & & & & & & & & \\
\hline $3 \mathrm{PH}$ & .05 & .18 & 1.00 & & & & & & & & & & & & & \\
\hline $4 M Q$ & -.06 & $.32^{*}$ & .05 & 1.00 & & & & & & & & & & & & \\
\hline $5 \mathrm{SSP}$ & $.28^{*}$ & $.21^{*}$ & .18 & $.34^{*}$ & 1.00 & & & & & & & & & & & \\
\hline 8 RE xp. & $.25^{*}$ & .07 & .04 & -.01 & $.23^{*}$ & .12 & .15 & 1.00 & & & & & & & & \\
\hline 9 SEP & .03 & $.22^{*}$ & $.19 *$ & .08 & .16 & .02 & .18 & .03 & 1.00 & & & & & & & \\
\hline 10 Stress & .06 & -.14 & $.19 *$ & .09 & .03 & .05 & -.13 & .07 & -.12 & 1.00 & & & & & & \\
\hline 110ptimism & .04 & $.19^{*}$ & .18 & .18 & .16 & .17 & .06 & .05 & $.27^{*}$ & -.15 & 1.00 & & & & & \\
\hline 12 Age & .13 & $-.19 *$ & $.20^{*}$ & .07 & .01 & .13 & .18 & .04 & .18 & .08 & .05 & 1.00 & & & & \\
\hline 16 SES & $.19^{*}$ & .05 & .16 & .15 & .08 & .03 & .04 & .12 & .10 & .06 & .14 & .01 & .07 & .18 & $.19 *$ & 1.00 \\
\hline \multirow[t]{2}{*}{ Mean } & 66.8 & 2.31 & 2.25 & 7.84 & 6.40 & 3.25 & 2.60 & 16.5 & 32.2 & 13.5 & 8.40 & 63.5 & - & 3.56 & 8.30 & 3.38 \\
\hline & 4 & & & & & & & 0 & 4 & 6 & & 0 & & & & \\
\hline S.D & 3.50 & 0.94 & 0.60 & 2.40 & 3.23 & 2.60 & 1.82 & .97 & 3.10 & 2.70 & 2.62 & 5.32 & - & .45 & 5.21 & 5.60 \\
\hline
\end{tabular}

Note: $N=284, L S=L i f e$ Satisfaction, Retirement Exp= Retirement Expectations, CES= Center for Epidemiologic Studies Depression Scale, SS=Social Status, FS=Financial Situation, AL=Activity Level, $\mathrm{PH}=$ Physical Health $M Q=$ Marital Quality, SSP=Social Support, RS=Retirement Status, JC=Job Challenges, RExp=Retirement Expectations, SEF=Self-Efficacy, S.D $=*$ Standard Deviation, ${ }^{*} \mathrm{p}<.05$ (2-tailed test). 
The bivariate correlations on Table 1 showed that financial situation, activity level, social support, retirement status (involuntary retirement), self-efficacy, stress and optimism had significant correlations with life satisfaction with correlations ranging from $r=.19$ to $r=.35 p<.05$, except marital quality, physical health, job challenge, retirement expectations, age and gender. All the independent (predictor) variables had significant negative correlations with depressive symptoms ( $r=-.19 p<.05$ to $r=-$ $.28, \mathrm{p}<.05$ ) except job challenge, age and gender. All the predictors correlated with each other with correlations ranging from $r=.01$ to $r=.35 p<.05$.

Regression analyses

The results in step 1 on Tables 2 and 3 show that age and gender did not predict psychological well-being among retired teachers. The results in step 2 on Tables 2 and 3 indicate that contextual variables made significant contribution to the prediction of psychological well-being, life satisfaction $\left(\Delta R^{2}=.26, F_{(12,272)}=15.74, p<.05\right)$; and depressive symptoms $\left(\Delta \mathrm{R}^{2}=.27, \mathrm{~F}_{(12,272)} 11.87, \mathrm{p}<.05\right)$. Results on Tables 2 and 3 indicate that retirement status (involuntary retirement), job challenges, financial situation, physical health, activity level and social support significantly predicted psychological well-being (life satisfaction and depressive symptoms). Therefore, Hypotheses $\mathrm{Hla}, \mathrm{HIb}, \mathrm{HlC}, \mathrm{Hle}, \mathrm{Hlg}$, and $\mathrm{HIh}$ were supported. These results suggest that retirement status (Voluntary retirement), adequate financial situation, adequate physical health, high activity level and high social support are related to high life satisfaction and low depressive symptoms. High job challenges had significant effect on lower life satisfaction and greater depressive symptoms among retired teachers. However, no significant effects of marital quality and social status on life satisfaction and depressive symptoms were found. Hence, hypotheses $\mathrm{H} 1 \mathrm{~d}$ and $\mathrm{HIf}$ were rejected. These results suggest that social status and marital quality had no tangible effects on life satisfaction and depressive symptoms among retired teachers.

Table 2: Hierarchical Regression analyses for testing moderating effects of gender for life satisfaction

\begin{tabular}{llllll}
\hline Variable & \multicolumn{3}{c}{ Life Satisfaction } & \multicolumn{1}{c}{ df } \\
\hline Step 1 & $\mathbf{R}^{\mathbf{2}}$ & $\Delta \mathbf{R}^{\mathbf{2}}$ & $\mathbf{F}$ & $\boldsymbol{\beta}$ & 2,282 \\
Age & .08 & & 1.52 & .02 & \\
Gender & & & .01 & 12,272 \\
Step 2 & .34 & .26 & $15.74^{*}$ & & \\
Contextual Variables & & & & $.33^{*}$
\end{tabular}


JC

Financial Situation

Physical Health

Activity Level

Marital Quality

Social Support

S.S

RS X Gender

JC X Gender

Step 3

Psychological Variables

PRE

Self-Efficacy

Stress

LOT-OPT
$-.36 *$

$.20 *$

$.23^{*}$

$.19^{*}$

.10

$.43^{*}$

.14

$.26 *$

$.29 *$

.54

.20

$17.63^{*}$

17,262

$.36 *$

$.43^{*}$

.$-.35^{*}$

$.46 *$

$.16^{*}$

Note: $\mathrm{N}=284, \mathrm{RS}=$ Retirement Status, JC=Job Challenge, SS=Social Status, PRE =Pre-Retirement Expectations, LOT-OPT=Life Orientation Test-Optimism, * ${ }^{*} p<.05$ (2-tailed test).

Results in step 3 on Table 2 and 3 indicate that psychological variables provided additional contribution to the prediction of psychological well-being life-satisfaction, $\left(\Delta R^{2}=.20, F_{(17,262)}=17.63, p<.05\right)$ depressive symptoms $\left(\Delta R^{2}=.17, F_{(17,262)}=14.56, p<.05\right)$. Results on Tables 2 and 3 further revealed that pre-retirement expectations, selfefficacy, perceived stress and optimism separately predicted life satisfaction and depressive symptoms of retired teachers. Therefore, Hypotheses $\mathrm{H} 5 \mathrm{a}, \mathrm{H} 5 \mathrm{a}, \mathrm{H} 5 \mathrm{c}$ and $\mathrm{H} 5 \mathrm{~d}$ were supported. These results indicate that higher pre-retirement expectations, self-efficacy, and optimism are related to higher life satisfaction and lower depressive symptoms. Also higher stress has negative effect on life satisfaction but positive effect on depressive symptoms among retired teachers.

Table 3: Hierarchical Regression Analysis for Testing Moderating effects of gender on depressive symptoms

\begin{tabular}{|c|c|c|c|c|c|}
\hline Variable & $\mathbf{R}^{\mathbf{2}}$ & $\Delta \mathbf{R}^{2}$ & $\mathbf{F}$ & $\beta$ & df \\
\hline Step 1 & .08 & & 1.56 & & 2,282 \\
\hline Age & & & & .08 & \\
\hline Gender & & & & .02 & \\
\hline Step 2 & .35 & .27 & $11.87^{*}$ & & 12,272 \\
\hline \multicolumn{6}{|c|}{ Contextual Variables } \\
\hline RS & & & & $-.28^{*}$ & \\
\hline $\mathrm{JC}$ & & & & $-.21^{*}$ & \\
\hline Financial Situatior & & & & $-.25^{*}$ & \\
\hline Physical Health & & & & $-.57^{*}$ & \\
\hline
\end{tabular}


$\begin{array}{ll}\text { Activity Level } & -.48^{*} \\ \text { Marital Quality } & -.08 \\ \text { Social Support } & -.35^{*} \\ \text { S.S } & -.10 \\ \text { RS X Gender } & .14 \\ \text { JC X Gender } & .09\end{array}$

$\begin{array}{lllll}\text { Step } 3 & .52 & .17 & 14.56^{*} & 17,262\end{array}$

Psychological Variables

PRE

$-.33^{*}$

Self-Efficacy $-.38^{*}$

Stress $.32^{*}$

LOT-OPT $-.38^{*}$

PRE X Gender $\quad .18$

Note: $\mathrm{N}=284, \mathrm{RS}=$ Retirement Status, JC=Jo b Challenge, SS=Social Status, PRE =Pre-Retirement Expectations, LOT-OPT=Life Orientation Test-Optimism, * $=p<.05$ (2-tailed test)

Moderator effects of gender

Results on Tables 2 and 3 in step 2 indicated that there were significant interaction effects of retirement status (involuntary retirement) $X$ gender (Beta=.26, $p<.05$ ) and job challenges gender (Beta=.29, $\mathrm{t}=3.34, \mathrm{p}<.05$ ) to predict life satisfaction but not depressive symptoms. Therefore, Hypotheses $\mathrm{H}_{2}$ and $\mathrm{H}_{3}$ were partially supported. However, pre-retirement expectations x gender interaction did not predict life satisfaction and depressive symptoms. Therefore, Hypothesis $\mathrm{H}_{4}$ was not supported.

\section{Discussion}

The purpose of this study was to examine the relationship between retirement context, psychological variables and psychological well-being. The moderator effects of gender on the retirement expectations -psychological well-being linkage were also investigated. Results from this study indicate that retirement context predicted psychological well-being. This is consistent with the findings of previous researchers who reported that retirement context such as retirement status (involuntary retirement), job challenges, financial situation, physical health and social support predicted psychological well-being (Ardelt, 1997; Bradley, Siegel \& Kasl, 2000; Gall \& Evans, 2000; Henkens, 1999; Kim \& Moen, 2002; Taylor, Golberg, Shore \& Lipka, 2008). However, the results contradicted the findings of Van Solinge and Henkens (2005) and Gall and Evans, (2000) who reported that financial situation, health, leisure activities, network, social status and job challenges had no significant effects on adjustment to retirement. 
These findings were because resources such as financial, personal, and social support served as mechanisms for explaining the link between retirement status and psychological well-being. The link is mediated by the changes in the resources which in turn predict changes in psychological well-being. Adjustment to retirement or psychological well-being in postretirement is influenced by the context in which the retirement transition occurs. The context is shaped by the resources available to the retirees and the circumstances in which retirement takes place. Given the context, individuals may experience retirement transition differently and therefore different psychological well-being.

Results from this study indicate that psychological variables (pre-retirement expectations, self-efficacy, perceived stress and optimism) predicted psychological well-being. These findings corroborate the work of previous researchers (Gall \& Evans, 2000; Van Solinge \& Henkens, 2005; Taylor \& Cook, 1995; Taylor et al, 2008) who found that pre-retirement expectations and self-efficacy were determinants of adjustment to retirement. These findings are attributed to the fact that retirement is not simply a state but a complex process embedded in some prior psychological resources. For example, retirees having higher self -efficacy, positive pre-retirement expectations and lower stress had higher life satisfaction and decreased depressive symptoms. The converse is also true. Therefore, variations in adjustment to retirement may stem from psychological factors that determine an individual's expectations of and responses to changes in retirement life.

That gender interacts with retirement status and job challenges to predict psychological well-being agree with the work of previous researchers who found strong gender differences with regard to adjustment to retirement (Schwarzer \& Schulz, 2002; Kim \& Moen, 2002; Van Solinge \& Henkens, 2005). These findings could be because women had different work histories, employment opportunities, and general life experiences which might make them to adjust to retirement differently than men do. Secondly, gender-based differences in work commitment, caused by the fact that women's primary role was in the home, are believed to result in fewer adjustment problems among women (Slevin \& Wingrove, 1995). In line with this reasoning, female retirees adjusted more easily than male retirees (Van Solinge \& Henkens, 2002).

Implications of findings

Findings from this study have implications for career, leisure and retirement counselling practice and assessment. An important implication is that the contextual and psychological factors examined in this study should be part of the investigation 
of those managing the mental and psychological well-being of retired teachers and others in retirement. Assessment of these factors will assist counsellors, psychologists and mental health practitioners to manage the retirees with depression better.

Pre-retirement expectations should be targeted in pre-retirement counselling. Providing education about life-style changes in retirement could assist retirees to come up with realistic retirement expectations. Helping retirees to build social relationships could be part of the pre-retirement counselling programmes especially for the retirees who expect health problems in retirement. Retirees who expect problems in retirement could also be educated on the positive impact of retirement. Cognitive- behavioural therapeutic intervention techniques would help retirees who consistently anticipate the negative while overlooking the positive aspects of retirement.

Postretirement counselling programmes that will involve leisure time activities (participation in community works) and vocational issues (developing skills for survival and self employment) should be designed to improve transition to retirement and enhance adjustment to life transition. The counselling programmes should also monitor changes in lifestyles and help retirees to re-evaluate their values and goals to be congruent with current experience of retirement. With early postretirement interventions, adjustment problems in retirement could be prevented thereby paving way for improved life satisfaction and decreased depressive symptoms.

While considering the results from this study, it is important to note some limitations. First there is no information on the pre-retirement well-being of the teachers which can be seen as an important factor in adjustment to retirement. Second, this study is cross-sectional in nature; as such it is not possible to establish cause and-effect relationship among the variables investigated. Future studies may include preretirement well-being of the retirees and carry out a longitudinal investigation in order to establish cause-and-effect relationship. Despite these limitations, this study has demonstrated that it is possible to identify potential indicators of psychological well-being of retired teachers.

\section{References}

Aquino, J.A, Russell, D.W., Cutrona, C.E, \& Altmaier, W.M. (1996). Employment status, Social support, and life satisfaction among the elderly. Journal of Counselling Psychology, 43,230-489.

Ardelt, M. (1997). Wisdom and life satisfaction in old age. Journal of Gerontology: 
Psychological Sciences, 52, 15-27.

Bandura, A. (1982). Self-efficacy mechanism in human agency. American Psychologist, 37,122-147.

Cohen, S., Kamark, T., \& Marmelstein,.R.(1983). A global measure of perceived stress. Journal of Health and Social Behaviour, 24, 385-396.

Cutrona, C.E. \& Russell, D.W. (1987). The provision of social relationships and adaption to stress. In W.H. Jones \& D. Perlman (Eds') Advances in personal relationships (vol. 1, 37-67), Greenwich, CT: JAI Press.

Gall, L.T., Evans, D.R. \& Howard, .J. (1997). The retirement adjustment process: changes in the well-being of male retirees across time. Journal of Gerontology, 52B (3), 110-117.

Gall, T.L. \& Evans, D.R. (2000). Pre-retirement expectations and the quality of life of male retirees in later retirement, Canadian Journal of Behavioural Sciences. 32 (3), 187-197.

Gallo, W.T., Bradley, E.H.; Siegel, M. \& Kasl, S. (2000).Health effects of involuntary job loss among older workers: Findings from the health and retired survey. Journal of Gerontology: Social Sciences; 55B S131-S140.

George, L.K. \& Maddox, G.L. (1977).Subjective adaption to loss of work role: A longitudinal Study. Journal of Gerontology, 32, 456-462.

George, L.T. (1993). Sociological perspective on life transitions. Annual Review of Sociology, 19,353-373.

Henkens, K. (1999). Retirement intentions and spousal support: A multi-actor, approach. Journal of Gerontology: Social Sciences, 54B S63-S74.

Kim, J.E \& Moen, P. (2002). Retirement transitions, gender and psychological well-being: A Life-course ecological model. Journal of Gerontology: Psychological Science, 57B, 212-222.

Kim, J.E. \& Moen, P. (1999). Depression and retirement. Journal of Depression and Anxiety. 10, 29.

Lee, Y. \& Lin, H. (2000). Leisure benefit as a mediator of the effects of leisure motivation in the formation on life satisfaction. Retrieved August 21, 2009 from http://bai2009.org/file/papers/1390.dc.

Marshall, V.W., Clarke, P.J. \& Ballantyne, P.J. (2001). Instability in the retirement transition: 
Effects on health and well-being in a Canadian study. Research on Aging, 23, 379-409.

Myers, S.M. \& Booth, A. (1998). Men's retirement and marital quality. Journal of Family Issues, 17, 336-357.

Midanik, L.T., Soghikian, K., Ranson L.J. \& Tekawa, L.S. (1995). The effect of retirement on mental health and health behaviours: The Kasiser Permanent Retirement Study. Journal of Gerontology Social Sciences, 50B, S59-561.

Moen, P. (2001). The gendered life course. In L.K.Geoerge \& R.H. Binstock (Eds.), Handbook of aging and the social Science, (5 $5^{\text {th }}$ ed., PP.179-196), San Diago, C.A: Academic Press.

Neugarten, B.L.; Havighurst, R.J. \& Tobin, S.S (1961). Measurement of life satisfaction. Journal of Gerontology, 16, 134-143.

Okatahi, A.O. (2007). Predisposing factors in the depression of retired teachers. Journal of Educational Research and Development. 2(2), 106-111.

Onyewotu, G, N. (2005). The issue of retirement, problems and challenges: Implications for counselling. Zaria Education; 1 (1), 131-137.

Radloff. L.S. (1977). The CES-D scale: A self-reported depression scale for research in the general population. Journal of Applied Psychological Measurement, 16, 385-401.

Richardson, V. \& Kilty, K.M. (1991). Adjustment to retirement: Continuity vs. discontinuity. International Journal of Aging and Human Development, 32, 151-169.

Ross, C. E. \& Drentea, P. (1998). Consequences of retirement activities for distress and the sense of control. Journal of Health and Social Behaviour. 39, 317-334.

Salami, S.O. \& Oduntan, H.O. (2001).Impact of socio-personal factors on the psychological adjustment of civil service retirees in Oyo state, Nigeria. African Journal of Educational Management, 9(2)1-14.

Scheier, M.F. \& Carver, C.S. (1993). On power of positive thinking: The benefits of being optimistic. Current Directions in Psychological Sciences, 2, 26-30.

Scheier, M.F.; Carver, C.S. \& Bridges, M.W.(1994). Distinguishing optimism from neuroticism (and trait anxiety, self-mastery, and self-esteem): A reevaluation of the Life orientation Test. Journal of Personality and Social Psychology, 67(6), 1063-1078. 
Schwarzer, R. \& Jerusalem, M. (1995). Generalized self -efficacy scale in J. Weiman, S.Wright \& Johnson (Eds'), Measures in health psychology: A users' portfolio, causal and control beliefs; PP.35-37, Winderser, UK NFER-NELSON.

Schwarzer, R. \& Schulz, U. (2002). The role of stressful life events. In A.M. Nezu, C.M. NezU \& P.A. Geller (Eds.), Comprehensive handbook of psychology: Health psychology (PP.2749). New York: Wiley.

Slevin, K.F. \& Wingrove, C.R. (1995). Women in retirement: A review and critique of empirical research since 1976. Social Inquiry, 65, 1-21.

Taylor, M.A. \& Cook, K. (1995). Adaptation to retirement: Role changes and psychological resources. Career Development Quarterly, 44, 67-82.

Taylor, M.A. \& Shore, L.M. (1995). Predictors of planned retirement age: Personal, Psychological and organizational factors. Psychology and Aging, 10 (1), 76-83.

Taylor, M.A; Goldberg, C.; Shore, L.M. \& Lipka, P. (2008). The effects of retirement expectations on post-retirement adjustment. Journal of Managerial Psychology, 23 (4), 458-470.

Van Solinge, H. \& Henkens, K. (2005). Couple's adjustment to retirement: A multi- actor panel study. The Journals of Gerontology Series B. Psychological Sciences and Social Sciences, 60(1), 11-20.

Vandewater, E, A.; Ostrove, J.M. \& Stewart, A.J. (1997). Predicting women's well-being in midlife: The importance of personality development and social role involvements. Journal of Personality and Social Psychology, 72, 1147-1160.

About the author:

Dr Samuel O.Salami received his Ph.D from the University of Ilorin, Ilorin Nigeria. He is a Senior Lecturer in Counselling Psychology at the Department of Guidance and Counseling, University of Ibadan, Ibadan, Nigeria but currently on Sabbatical leave in the Kampala International University, Kampala, Uganda. His research interests include mentoring, leadership, employee commitment, job attitudes, career development, organizational conflict resolution and occupational stress. His research has been published in the Europe's Journal of Psychology, European Journal of Scientific Research, Career Development International Journal, Journal of Workplace learning, Women in Management review and International Journal for the Advancement of Counselling.

Address for correspondance: drsosalami2002@yahoo.co.uk 